\title{
Uniting epistemological perspectives to support contextualized knowledge development
}

\author{
Sara van der Linden ${ }^{1} \cdot$ Susan McKenney ${ }^{1}$
}

Published online: 27 April 2020

(C) The Author(s) 2020

\begin{abstract}
The nature of knowledge and how it is developed have been debated in philosophy and research for centuries. In the literature on teachers' knowledge, two perspectives have been particularly visible. One perspective stresses cognitive processes and deliberate knowledge acquisition. Another perspective stresses the situated nature of teachers' learning and knowledge development through awareness. This theoretical article proposes that uniting both epistemological perspectives is beneficial for developing teachers' contextualized knowledge of how to teach at all phases of career development, and especially early on. In so doing, action and reflection are positioned as central to the development of teachers' knowledge, and affordances from both the deliberate and the aware perspectives are articulated. Specifically, this article explains why uniting the two perspectives supports better sense-making, more refined instructional planning, and more responsive teaching, before offering a united reflection model. These processes are then discussed in the context of video coaching interventions for early-career teachers. After presenting a blueprint for video-based reflection and key design features that could support teachers' learning, important differences compared to other reflection models are discussed and implications for (the design of) teachers' professional development based upon this united perspective are presented.
\end{abstract}

Keywords Teacher reflection - Teacher cognition - Epistemology · Teacher effectiveness · Video coaching $\cdot$ Instructional design

\section{Introduction}

Epistemology is the field of philosophy concerned with "the possibility, nature, sources and limits of human knowledge" (Sumner 2006, p. 94). For centuries, there have been varied perspectives on the nature of knowledge and how it is developed, including empiricism, idealism, rationalism, constructivism, and pragmatism. When it comes to these perspectives in relation to teachers' knowledge, we note that two epistemological perspectives have

Sara van der Linden

sara.vanderlinden@utwente.nl

1 ELAN, Department of Teacher Development, University of Twente, Enschede, the Netherlands 
been particularly visible in the literature. One stresses cognitive processes, and the other stresses the situated nature of teachers' knowledge.

The first perspective is aligned with empiricism, and positions knowledge as accepted truths that arise through systematic observations. These can be verified and tested, and therefore generalized until new observations cause one to discard those provisionally accepted truths. From this perspective, teachers' knowledge includes a collective knowledge base on teaching that is commonly accepted (Carlson and Daehler 2019). Individual knowledge acquisition as viewed within this perspective can be measured outside of teaching practice (e.g., Kaiser et al. 2017), for example by identifying certain behaviors in examples of practice. Central to this perspective is the deliberate attention to how one's teaching relates to collective understandings of effective teaching behaviors.

The second perspective aligns with a form of rationalism. Closely connected to constructivist perspectives, this view positions knowledge as truth that is constructed within specific contexts and therefore explicitly linked to the individual knower (Sumner 2006). This perspective acknowledges that much of teachers' knowledge is also personalized (Carlson and Daehler 2019), can only be developed in and through practice (Depaepe et al. 2013), and is sometimes tacit. Tacit knowledge, which supports intuitive understanding and decision-making (Eraut 2000), can be understood as norms or dispositions that guide our actions (Herbst and Kosko 2014) and has also been described as what we know, but cannot tell (Polanyi 1967). This type of knowledge can be accessed when analyzing teaching or learning using representations of practice (Herbst and Kosko 2014). Central to this perspective is an awareness of the learners' needs, the school context, and one's place in it.

If these two perspectives are viewed as entirely mutually exclusive alternatives, then it would be difficult to reconcile them, since the first stresses the view that knowledge exists separate from the knower, while the second stresses its inherent connection to the knower. But here, we embrace both perspectives, and submit that these types of knowledge can and do coexist. Further, we note that each has implications for understanding teachers' cognition and resulting knowledge acquisition. In addition, we argue that attending to both maximizes the potential for experiencing the affordances of a deliberate, often deductive mindset as well as an aware, often inductive mindset.

While epistemological perspectives can have implications for designing education and training, Kirschner (2009) reminded us not to confuse them with the psychological bases of learning and the pedagogical bases of teaching. In particular, he pointed to the need to select pedagogies based on whether the learners are novices or experts. According to Kirschner (2009), novices still need to acquire knowledge, whereas experts already have integrated knowledge bases in which universal truths have been contextualized through experiences. Building on this observation, it is proposed that novices in the teaching profession, early career teachers (ECTs), can benefit from learning experiences that prompt the acquisition of both collective and tacit knowledge, while also providing opportunities to integrate those understandings into their growing knowledge bases. Given that novice teachers need to sustain and strengthen their effective teaching practices in context (Feiman-Nemser 2001), bringing together these two perspectives seems particularly powerful for them.

Thus, this paper argues that it can be consistent and productive to acknowledge that there are different types of knowledge and therefore, multiple pathways to knowledge acquisition. It further advocates the need to consider implications for instructional design based on the stance that teaching is a complex endeavor which requires the integration of knowledge about universal truths with understanding of contextual needs, opportunities, and constraints. Reflection is proposed as a key driver for knowledge acquisition in both 
perspectives. Within this article, Dewey's (1933) conceptualization is used, which defines reflection as the "active, persistent and careful consideration of any belief or supposed form of knowledge in the light of the grounds that support it and the further conclusions to which it tends..." (p. 9). Within the perspective based on empiricism, it is imperative that teachers reflect on their teaching in reference to standards that represent indicators of effective teaching practices. And within the perspective based on rationalism, it is imperative that teachers reflect on salient moments in their practice, taking into account the needs of learners, the school context, and their place in it. While the current literature offers some guidance for reflection, it lacks an integration of the two perspectives described here, guidelines for supporting such reflection in general, and specific considerations for implementation.

This paper looks specifically at the integration of these two perspectives in the context of video coaching. Here, we define video coaching as a professional development approach in which teachers and coaches record instances of teaching and engage in video-based discussions in a sustained manner. Video coaching affords opportunities for reflective practice, which is especially useful for studying complex classroom interactions, provoking discussions, and supporting demonstration of events that are difficult to describe to others (Marsh and Mitchell 2014). Our review of the video coaching literature (van der Linden et al. manuscript in preparation) revealed two dominant views, which align with the two epistemological stances described here. For example, My Teaching Partner (Pianta et al. 2008) is a video coaching program that is more closely connected to empiricism, in which the CLASS teaching effectiveness framework is used as a measure for improving practice. In this program, teachers' videotaped practice is compared to teaching effectiveness standards during coaching and the results of these discussions are used as input for making changes in the classroom. By contrast, video clubs are video-based professional development environments where groups of (mathematics) teachers led by researcher-facilitators watch videos excerpts from their own practice to enhance their professional vision, their ability to notice important classroom moments (Sherin and van Es 2009). More closely connected to rationalism, these meetings feature no a priori standards that are used to view practice; rather, teachers are guided to focus on and understand student (mathematical) thinking, and thereby developing the ability to notice salient features of classroom practices (Sherin and van Es 2009). Both video coaching approaches have value for the development of teachers' knowledge, but an integrated approach might offer additional value. Therefore, to support the work of coaches, teacher educators, and (teacher) education researchers, this paper elaborates upon the above argument, presents a conceptual model for supporting teachers' learning through reflection that brings the two perspectives together, and discusses key design features of video coaching for ECTs (see Fig. 1 for an overview).

\section{Theoretical framework}

This article builds on the recent work of scholars who have acknowledged the importance of attending to both perspectives for understanding teachers' knowledge, and who have advocated a more integrated approach (e.g., Carlson and Daehler 2019; Depaepe et al. 2013; Kaiser et al. 2017). It is important to state that these two views characterize two basic ways in which knowledge is acquired and what knowledge is, and are not labels for types of teachers, teacher educators, or teacher education researchers. This section explains why uniting both epistemological perspectives is beneficial for helping novice teachers, in particular, to develop contextualized knowledge of how to teach. First, the origins and habits 


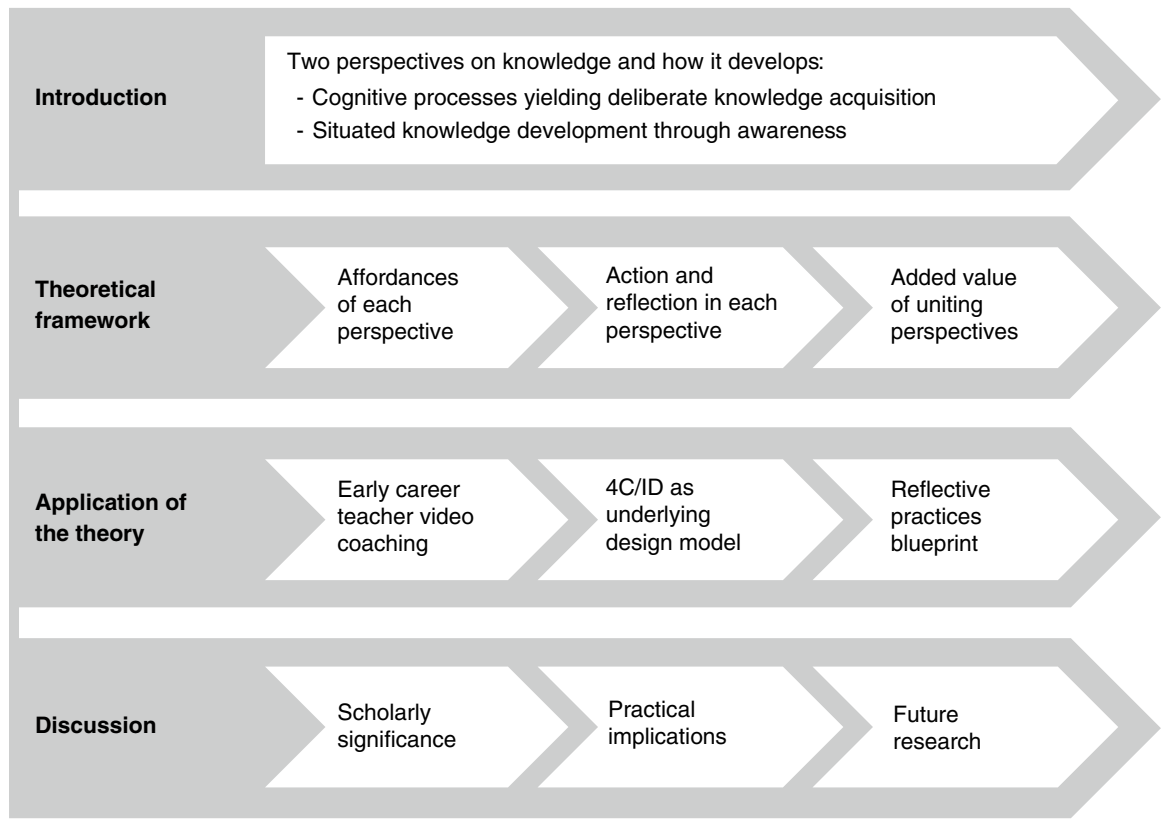

Fig. 1 Graphic organizer of this article

of mind related to both the deliberate and the aware perspectives are presented. Next, relationships between teacher action, that is, providing instruction, and reflection are discussed in general, and from each perspective. Finally, the added value for teachers' knowledge development of bringing together the two perspectives is articulated and a united reflection model is presented.

\section{Affordances of each perspective}

\section{Deliberate: understanding practice in reference to standards}

Aligned with empiricism, a deliberate perspective positions individual teachers' cognition as based on their acquisition of collective knowledge of teaching and learning, which serves as a frame of reference for developing their professional practice. Collective knowledge consists of commonly accepted truths about teaching and learning, within and across teaching domains, which have been developed by experts and practitioners, and have been verified in different contexts (Carlson and Daehler 2019). This type of knowledge is often taken to include Shulman's (1987) content knowledge (CK), pedagogical knowledge (PK), and pedagogical content knowledge (PCK) (Kaiser et al. 2017). Individual acquisition of collective knowledge can be evaluated through multiple choice testing, as described elsewhere (e.g., Kaiser et al. 2017). While this type of knowledge can be acquired and measured outside of teaching practice, it can also be applied to practice, and could provide opportunities for the professional development of teachers. Frameworks of effective teaching practices can be used as lenses to observe isolated behaviors and to investigate the extent to which current teacher practices match these standards. As a result, teachers 
could gain understanding of their practice in reference to the standards of effective teaching. Structured reflection before, after, or even during teaching can facilitate knowledge development from this perspective.

\section{Aware: understanding the context and one's place in it}

Aligned with rationalism, an aware perspective positions (teachers') knowledge as often tacit, developed through (inter)action with the context and within local systems (Brown et al. 1989; Lave and Wenger 1991). This is often characterized as (intuitively) knowingto-act within a certain context (Depaepe et al. 2013) and is constructed through the actors' interpretations of the local context, therefore being inextricably tied to the actor (Sumner 2006). Consequently, this type of knowledge can only be measured and developed when teachers engage in practice, through enactment, planning, or reflection activities (Carlson and Daehler 2019). In addition, the sense of control over one's everyday practices, or agency, is " $\ldots$ also shaped by the structures and cultures within which teachers work" (Biesta et al. 2017, p. 39). As such, teaching is not only determined by personal attributes, but is also dependent on the interplay between the teacher and the context. Thus, the teacher's own understanding of who they are within their professional context (identity) shapes actions and over time, and conversely, actions also shape identity (Buchanan 2015). From the aware perspective, discussion of teachers' own practice is promoted, a phenomenon which supports sensemaking and the shaping of one's own views of possible changes within the environment (Biesta et al. 2017; Sherin and van Es 2009; van Es and Sherin 2008). As a result, teachers gain understanding of their context, and their agency within it. So, like with the deliberate perspective, knowledge development from the aware perspective can be served by reflecting on what has transpired in the classroom, reflecting on classroom aspirations while planning lessons, and by reflecting while teaching.

\section{Reflection and action}

\section{How reflection and action support knowledge development}

Reflection is an important process that can support teachers to develop content knowledge, pedagogical knowledge, and pedagogical content knowledge (Hoffman-Kipp et al. 2010). As described previously, Dewey (1933) considered reflection to be a mindful review of what is known, how this is known, and the implications it has. Therefore, reflection by teachers can be understood as the consideration of teachers' own knowledge of how to teach, which could be grounded in accepted understandings and/or experiences from their practice. Here, reflection is considered in light of both epistemological perspectives.

Reflection from a more deliberate perspective, sometimes referred to as technical reflection (Lindsay and Mason 2000; van Manen 1977), is a type of reflection in which teachers consider the quality of their practice in light of evidence-based standards. This type of reflection requires teachers to articulate their understandings of insights developed by others (e.g. teaching effectiveness standards), consider their practice in light of this framework, and determine if and to what extent, their practice meets these standards. Such an analysis provides insight into their current state of performance, the desired state of performance, and the difference between the two. The difference between the current and the desired states then guides further actions. Despite well-articulated affordances of this kind of approach (van der Lans et al. 2018), it has long been argued that such a view of reflection 
is one-sided (van Manen 1977), and could limit the potential richness of reflective practice. For example, educators and school leaders have acknowledged the importance of developing intuition for decision making in classroom contexts (Sipman et al. 2019), showing that, alongside an appreciation for evidence, stakeholders also attach relevance to additional facets of teachers' knowledge development.

Reflection has also been approached from a more aware perspective, aiming to help teachers develop insight into the local context, and knowledge that is more finely tuned to situational needs and constraints. For example, teachers who participated in video clubs noticed more important teaching moments in practice after the last session (Sherin and van Es 2009). This kind of reflection often relies heavily on social discourse communities (Ovens 2002), in which teachers collaboratively negotiate their contextual understandings in order to develop new ones, as has been witnessed in video clubs for literacy or mathematics education (e.g., Wallin and Amador 2019; Walsh et al. 2020). As with the deliberate perspective, such an analysis provides insight into the current contextual state, the desired contextual state, and the difference between the two. Discrepancies between states holds implications for further actions, ideally taking into account the needs of the learners, as well as the opportunities and constraints that are inherent to the local setting. This view specifically incorporates the idea of tailoring products to fit the needs of the learners and to the environment in which they will be implemented (McKenney 2013).

In summary, the two perspectives on reflection can provide insight into the current state of affairs, the desired state of affairs, and the implications of each when compared, but their focus is different. Obviously, the proposed outcomes of reflection, that is the gap between the current state and the desired state, are closely connected to Vygotsky's zone of proximal development (1978), who positioned the potential development of children as the difference between the current developmental level as far as individual problem solving and the potential developmental level that could be reached with guidance of a more knowledgeable peer or teacher. While reflection from the deliberate perspective provides insight into performance in relation to a certain standard, reflection from the aware perspective provides insight into needs, opportunities, and constraints for growth within the local context. The different proposed outcomes of reflection build on Vygotsky's zone of proximal development (1978) as well as McKenney's (2013) zone of proximal implementation for technology innovations in schools. Relating to teaching, these are:

- $Z P P$ The Zone of Proximal Performance highlights understanding of collective teaching knowledge and acting upon this knowledge, specifically targeting the difference between the pre-determined, explicated teaching behaviors individual teachers can execute on their own, and those they could identify and perform with guidance.

- ZPI The Zone of Proximal Implementation highlights situated understanding and acting upon this understanding, specifically targeting the difference between the learner, classroom, and school-related insights that individual teachers can develop and apply on their own, and those they could identify and implement with guidance.

\section{Temporal differences in reflection and action}

The reflection-action relationship can be further detailed in whether teachers are thinking about the past, future, or present. The first type of reflection is a retrospective process, referred to as reflection on action (RoA) (Schön 1983), retrospective reflection (Loughran 1996), or retroactive reflection (Mezirow 1991). Causal reasoning can be useful during 
reflection on action, as this type of reasoning allows learners to explain phenomena and solve problems (Jonassen and Ionas 2008). During reflection on action, teachers look back, consider their existing teaching practices, and reframe their understandings of their ZPP and ZPI.

A different type of thought process is required to consider how these understandings can be translated to (changes in) practice. This second type of reflection has been referred to as anticipatory reflection (Loughran 1996), though we prefer to describe it as reflection for action (RfA). This can be understood as a planning process, where teachers engage in reasoning to connect their teaching practices (and their implications for students) to inform instructional decision making (e.g., Loughran et al. 2008). Through this kind of causal reasoning, teachers consider how instructional changes could affect student outcomes, based on their understanding of (co-occurring) cause-effect relationships as well as any mediating processes (cf. Jonassen and Ionas 2008). This process could inspire the design and/or construction of actionable plans or lesson materials that can support practice. The plans or actions that are developed bridge the gap between current practice and the desired practice, thus supporting development within one's ZPP and ZPI.

Finally, the third type of reflection occurs during the action itself, referred to as reflection in action (RiA) (Schön 1983), contemporaneous reflection (Loughran 1996), or thoughtful action (Mezirow 1991). This type of reflection is based on the idea of knowingin-action (Schön 1995), or simultaneous thinking and acting that guide decision-making processes during teaching. This knowing-in-action includes not only the action itself, but also the perception and judgment of salient moments and the responses triggered (Schön 1995). The results of RiA are visible in terms of (improved) performance and implementation. Next, the added value of uniting epistemological perspectives within reflection is described.

\section{Uniting epistemological perspectives}

By considering the three types of reflection (RoA, RfA, RiA) in light of the two epistemological perspectives (deliberate and aware), six reflective processes can be derived. While these reflection processes have value on their own, uniting the two perspectives could yield better sense-making, better instructional planning, and more responsive teaching. Here, the implications for each type of reflection respectively (RoA, RfA, and RiA) from each perspective are described and illustrated with examples, and summarized in Fig. 2.

Considering $R o A$, "[This] sense-making is generally defined as an (inter)active and dynamic process by which individuals and groups make meaning from the environments in which they operate, which in turn orients their actions" (März and Kelchtermans 2013, p. 15). During deliberate analysis of practice, teachers use an explicit frame of reference to engage in knowledge-driven processing and identify evidence-based norms in action. By interpreting their performance in reference to these norms, they gain insight into their ZPP. By contrast, explicating awareness entails having teachers engage in context-driven processing to identify salient moments in practice, interpret them, and articulate insights into their ZPI. Uniting these perspectives would require teachers to compare their ZPP with their ZPI during RoA activities. Together, these views would paint a more complete picture of the situation at hand, because teachers would not only gain understanding of their performance relative to a set of standards, but this set of teaching practices is also compared to the context in which these actions are enacted to determine what is needed. This provides 


\begin{tabular}{|c|c|c|c|}
\hline & $\begin{array}{l}\text { DELIBERATE } \\
\text { PERSPECTIVE } \\
\text { Knowledge-based } \\
\text { processing by } \\
\text { focusing on } \\
\text { evidence-based norms } \\
\text { and the implications } \\
\text { for one's own ZPP }\end{array}$ & $\begin{array}{c}\text { ADDED VALUE OF } \\
\text { UNITING PERSPECTIVES } \\
\text { Contextualizing } \\
\text { knowledge } \\
\text { of how to teach }\end{array}$ & $\begin{array}{c}\text { AWARE } \\
\text { PERSPECTIVE } \\
\text { Context-based } \\
\text { processing by } \\
\text { focusing on } \\
\text { salient moments } \\
\text { and the implications } \\
\text { for one's own ZPI }\end{array}$ \\
\hline $\begin{array}{l}\text { Reflection } \\
\text { ON Action }\end{array}$ & $\begin{array}{l}\text { What: Deliberate } \\
\text { analysis of practice } \\
\text { Why: Improve } \\
\text { understanding of } \\
\text { ZPP }\end{array}$ & $\begin{array}{l}\text { Added value: Better } \\
\text { sense-making } \\
\text { How: Complete } \\
\text { picture to guide } \\
\text { understanding }\end{array}$ & $\begin{array}{l}\text { What: Explicating } \\
\text { awareness } \\
\text { Why: Improve } \\
\text { understanding of } \\
\text { ZPI }\end{array}$ \\
\hline $\begin{array}{l}\text { Reflection } \\
\text { FOR Action }\end{array}$ & $\begin{array}{l}\text { What: Deliberate } \\
\text { planning } \\
\text { Why: Improve } \\
\text { planning according } \\
\text { to ZPP }\end{array}$ & $\begin{array}{l}\text { Added value: Better } \\
\text { planning } \\
\text { How: Complete } \\
\text { picture to guide } \\
\text { planning }\end{array}$ & $\begin{array}{l}\text { What: Planning } \\
\text { based on awareness } \\
\text { Why: Improve } \\
\text { planning according } \\
\text { to ZPI }\end{array}$ \\
\hline $\begin{array}{l}\text { Reflection } \\
\text { IN Action }\end{array}$ & $\begin{array}{l}\text { What: Deliberate } \\
\text { practice } \\
\text { Why: Improve } \\
\text { action within } \\
\text { ZPP }\end{array}$ & $\begin{array}{l}\text { Added value: More } \\
\text { responsive teaching } \\
\text { How: Awareness } \\
\text { of cause-effect } \\
\text { between action-reaction }\end{array}$ & $\begin{array}{l}\text { What: Practicing } \\
\text { awareness } \\
\text { Why: Improve } \\
\text { awareness within } \\
\text { ZPI }\end{array}$ \\
\hline
\end{tabular}

Fig. 2 United reflection model

a rich understanding of the effectiveness of the actions within specific contexts and offer directions for refinement of practices in tune with the local environment.

With regard to $R f A$, teacher instructional planning can be defined as the process of determining learning objectives, making pedagogical decisions, selecting learning activities, selecting assessment methods, and selecting tools and resources to support learning (Harris and Hofer 2009). Deliberate planning features teacher use of an explicit frame of reference to generate evidence-based ideas for improving practice, based on the outcomes of RoA. This is then used to anticipate how performance could improve, and plan actions in line with their ZPP. By contrast, planning based on awareness features identification of salient moments in their practice and the generation of ideas about how to improve their practice. This information is subsequently used to anticipate how implementation could improve by adjusting these practices, planned in line with the teacher's ZPI. Uniting the deliberate and aware RfA processes would result in planning that attends to frameworks of effective teaching to design teaching scenarios, as well as the adaptation of these to the needs and constraints of 
the learners, classroom, and school context. This could provide solutions that are both effective and feasible, while also meeting the standards of the school context in which they are to be implemented.

Uniting the deliberate and aware perspectives during RiA could potentially lead to more responsive teaching, namely, the ability to perceive, judge and respond to interactions in the classroom. Deliberate practice involves the use of an explicit frame of reference to monitor one's own practice in reference to evidence-based norms (Hatton and Smith 1995), and adjusting one's practice within one's ZPP. Practicing awareness involves context-based identification of salient moments in practice, direct interpretation of these salient moments, and immediate action within the ZPI. Uniting the two perspectives could support teachers in monitoring their own actions, as well as in monitoring the feedback that is received as a consequence of those actions. Heightened awareness of the context and the way actions affect that context might provide insight into the cause-effect relationships between teacher actions and student reactions, and offer opportunities for in-the-moment adjustment of practice (if the teachers' repertoire already includes alternatives). Next, the united reflection model will be applied to an instructional design for video coaching for Early Career Teachers (ECTs).

\section{From theory to practice}

\section{A rich context for united reflection}

\section{Early career teachers}

Although it's important to provide differentiated pedagogy for experts as compared to novices [according to Kirschner (2009)], the united reflection model holds potential value for all teachers, and it seems particularly beneficial for those with less experience, that is ECTs. These teachers have not yet acquired the same level of knowledge and skills as their more experienced colleagues (Maulana et al. 2012; van de Grift 2010), which is important to address, since teaching quality has an effect on student learning gains (Hanushek and Rivkin 2010). And even though pre-service programs can be of excellent quality, ECTs still need to develop their professional identity and professional practice within new settings (Feiman-Nemser 2001). Further, novice teachers experience a variety of challenges, such as those pertaining to job characteristics, school characteristics, and poor relationships with students or colleagues (den Brok et al. 2017; Smith 2014), and a combination of these factors might be the reason for higher teacher attrition during the early years of teaching (den Brok et al., 2017). Feiman-Nemser (2001) identified a number of important learning tasks for ECTs: (1) gaining local knowledge of students, the curriculum, and school context; (2) designing responsive instruction; (3) enacting a beginning teaching repertoire; (4) creating a classroom learning community, and (5) developing a professional identity. Thus, professional development for ECTs should not only include opportunities to enhance knowledge and skills related to effective teaching and the local context, but also allow questioning of one's understandings of the self, others, and one's performance. Reflection affords opportunities to undertake these crucial learning tasks. 


\section{Video coaching}

Reflection can be structured in many ways, and since video coaching has been shown to be powerful for supporting teacher performance and literature provide examples (e.g. Pianta et al. 2008; Sherin and van Es 2009), from both epistemological perspectives (van der Linden et al. manuscript under preparation), it seems plausible that it can help address some of the challenges that ECTs face. As mentioned previously, video coaching constitutes a professional development approach in which teachers and coaches record instances of teaching (opportunities for RiA) and engage in video-based discussions (RoA, RfA), in a sustained manner. Research has shown that the strophic interaction between teaching in action and reflection thereon play a crucial role in teacher professional growth (Clarke and Hollingsworth 2002) and this process could support ECTs in studying their practice, getting acquainted with the local setting, developing and sustaining effective teaching practices, and negotiating their identities. Video coaching can provide a reflection-rich context for ECTs in which united epistemological perspectives on teachers' knowledge could be beneficial. A core assumption underlying the present work is that this type of professional development can allow teachers to reflect: on action using video to gain insight into the existing situation, for action to develop plans that can support their practice, and in action to adjust their practices. The following two sections describe how this can be accomplished.

\section{Supporting complex learning}

Developing new knowledge through action-reflection interaction, especially as part of video coaching, constitutes a complex learning task. It requires teachers to integrate reflection perspectives, to coordinate the requisite skills, and to apply their new insights to practice. Guidelines on how to support such complex learning have been provided in the literature on instructional design. In particular, the Four Components Instructional Design (4C/ID) model (Van Merriënboer and Kirschner 2017) is well-suited to supporting the kind of complex learning that ideally takes place during video coaching. In a variety of professional situations, this holistic approach has been shown to stimulate the integration of knowledge, skills and attitudes (often referred to as competencies), thus mitigating the compartmentalization of learning tasks or fragmentation of constituent skills (Van Merriënboer and Kirschner 2017). This model prompts designers to create authentic learning experiences that approximate real life, increase in complexity, and are clearly meaningful to the learners. The remainder of this section describes the four instructional components that should be included in video coaching based on the united reflection model in order to support complex learning: (1) whole learning tasks, (2) procedural information, (3) supportive information, and (4) part-task practice (Van Merriënboer and Kirschner 2017).

\section{Whole learning task: reflection from united perspectives}

The whole task of united reflection, like other learning tasks, should be organized in task classes that are ordered from less complex to more complex (van Merriënboer and Kirschner 2017). Bloom's revised taxonomy proposes that cognitive processes can be understood as involving sequential levels of complexity (Krathwohl 2002). Broadly, 
these are (from least to most complex): remember, understand, apply, analyze, evaluate, create (Krathwohl 2002). With regard to reflection, the temporal focus influences the level of complexity. Here, we describe how each of these (RoA, RfA, and RiA) maps to a different task class.

$R o A$ is classified as the least complex, because it requires teachers to identify and interpret events that align with frameworks and (other) salient moments in videotaped practice. Teachers elaborate on their understanding through reasoning, for example, regarding teacher-student interactions. Judgments concerning how well teachers' actions comply with collective knowledge about teaching or whether students are learning require teachers to remember and analyze their findings.

RfA requires teachers to apply collective and tacit knowledge to more or less familiar problems, rendering it medium complex. Here, teachers must have an idea of the problem situation and modify collective and tacit knowledge to fit the specific problem at hand. In addition, teachers must critique whether their proposed alternative scenarios are compatible with collective knowledge about effective teaching and/or emic insights about the context, which implies a predictive kind of evaluation process. In some cases, this might require teachers to create new products, and go through the stages of problem representation, generating alternatives, planning, and constructing.

$R i A$ is considered the most complex, because it combines all of the above-mentioned cognitive processes in order to create and adjust practices in the moment. Teachers enact their teaching routines while monitoring the students' feedback and their own actions, and interpreting the classroom feedback to judge if instruction is having the desired effect. They often need to create alternative teaching scenarios on the spot.

\section{Procedural information: reflection steps}

Procedural information involves how-to information or step-by-step instructions on recurrent task aspects (van Merriënboer and Kirschner 2017). The 4C/ID model explains that procedural information is needed in order to automate certain aspects of the task, which allows learners to allocate their conscious cognitive processing to the non-recurrent aspects of the tasks. Here, recurrent aspects within the whole task of united reflection are considered.

"To reflect is to look back over what has been done so as to extract the net meanings which are the capital stock for intelligent dealing with further experiences" (Dewey 1938, p. 86, emphasis not in original). Consistent with this description of the process (and in the context of engineering design), Reymen et al. (2006) described a generic three-step procedure for reflection, consisting of (1) preparation, (2) image forming, and (3) conclusion drawing. Here, these steps are considered in light of the united perspectives, and summarized in Table 1.

The first step, preparation, refers to how practitioners (teachers) portray or understand the (classroom) situation (Berland and Hammer 2012; Schön 1983). The way teachers frame the situation influences their practice (Russ and Luna 2013), because the frame that is being applied to a certain situation influences expectations and the way it will be interpreted (Berland and Hammer 2012). This first step requires practitioners to detail the reflective question and to collect facts related to it (Reymen et al. 2006). Deliberate framing is guided by frameworks for effective teaching, whereas aware framing arises from attention to the teaching context and one's place in it. 


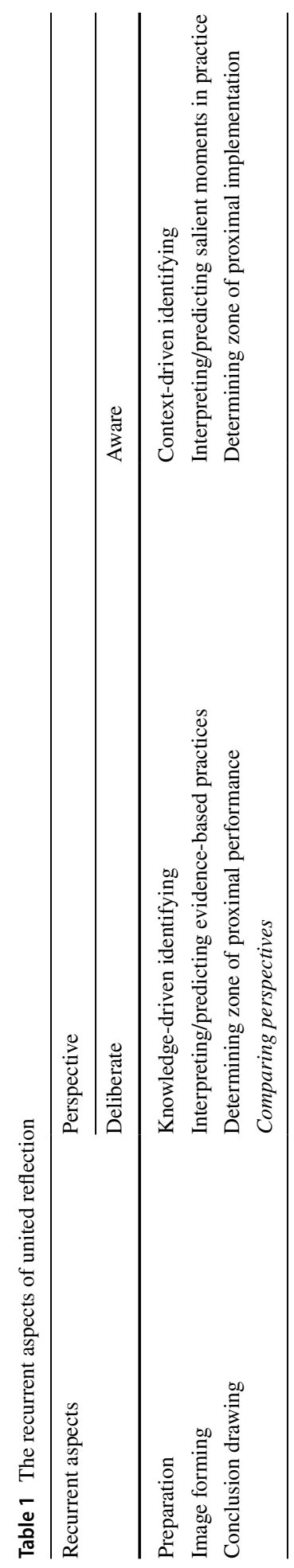


The second step, image forming, requires practitioners to investigate the phenomena identified during the first step (Reymen et al. 2006), by using the framing to interpret (or anticipate) the teaching situation. Interpretation is regarded as an important process component of teachers' competence (Blömeke et al. 2015; Santagata and Yeh 2016), and has been described as making sense of salient features of classroom interactions (Sherin and van Es 2009), or explaining perceptions of teaching and learning processes in order to examine the effect of teaching decisions on student outcomes in line with the learning goals (Santagata and Yeh 2016). Deliberate image forming is focused on sensemaking about the (proposed) alignment between frameworks of effective teaching and practice, whereas aware image forming is focused on making sense of the interplay between actors and the contextual needs and constraints.

The third step, is conclusion drawing. It can be used to inform decision making or lead to reframing. It requires practitioners to contrast their findings from image forming and consider the implications for practice (Reymen et al. 2006). From the deliberate perspective, conclusion drawing is focused on determining (considerations within) the ZPP, whereas conclusion drawing from the aware perspective is focused on determining (considerations within) the ZPI.

\section{Supportive information: scaffolding cognitive processes}

Supportive information provides a bridge between what learners already know and what they need to know (van Merriënboer and Kirschner 2017). This type of information is directed towards supporting teachers in the novel aspects within the six recurrent tasks (shown in Table 1). Supportive information consists of domain-specific information, examples of domain-specific information, and cognitive feedback (van Merriënboer and Kirschner 2017). This section examines supportive information relevant to the three steps described above.

The framing undertaken during preparation is a cognitive process that shares common characteristics with other attentional processes described in the literature, such as noticing student thinking (Sherin and van Es 2009; van Es and Sherin 2008); perceiving particular events during instruction (Kaiser et al. 2015); and focus selection (Santagata and Yeh 2016). Research has shown that framing can be difficult for (novice) teachers, because they are inclined to attend to surface-level events instead of salient classroom moments (Sherin and van Es 2009; Wolff et al. 2017). Domain-specific information to support framing includes frameworks of effective teaching (deliberate perspective) or literature on noticing student learning (aware perspective). In addition, problem-solving guidance, such as guiding questions to focus ECTs' attention on priorities, could support this cognitive process (Sherin and van Es 2009). Support could also take the form of watching other ECTs framing teaching issues while thinking aloud about the way these behaviors might be observed in practice. Finally, cognitive feedback could consist of including opportunities for ECTs to compare their framing of the problem to the work of other ECTs or the coach.

Next, teachers need to interpret or anticipate teaching experiences. Interpretation can be difficult for teachers, because they are inclined to describe or quickly judge a situation instead of engaging in deeper reflection (Sherin and van Es 2009). Moreover, novice teachers can experience difficulty doing this without the help of a knowledgeable other (Gelfuso and Dennis 2014). In addition, teachers do not always engage in developing explanations to fully grasp the nature of the problem, but jump to generating solutions through brainstorming (Boschman et al. 2014). Anticipating future actions supports teachers' learning when 
teachers engage in reasoning and justification processes instead of only brainstorming (Voogt et al. 2016). Without guidance, teachers' anticipatory reflections are often focused on practical issues, instead of the substantive issues (Voogt et al. 2016). Guiding questions for retrospective reasoning from a deliberate perspective could include: To what extent does the [recorded behavior] align with the framework? Why do you think that? Coaches could also model interpretive and anticipatory reasoning, and exemplify how to make sense of the connection between teacher actions and student learning. Produced artifacts, such as video annotations created during RoA, could serve as examples, but can also be examined and compared for the logic of reasoning about cause and effect, or the extent to which they convey a clear message and can thus be used as input for cognitive feedback.

Finally, teachers need to contrast their findings within perspectives in order to draw conclusions about their ZPP and ZPI, and doing so between perspectives can guide further actions. Examples of problem-solving guiding questions for drawing conclusions during deliberate RfA could be: What conclusions do you draw based upon consideration of different learning scenarios? What theoretical evidence did you find that supports your design choices? In addition, a worked example that illustrates how conclusions follow from the framing and interpretation processes could help teachers understand the process. Lastly, artifacts produced during the framing and interpretation/anticipation processes could be compared to the conclusion drawn about the ZPP and ZPI to check for logic and to what extent the initial question has been answered, which could provide cognitive feedback on the conclusion-drawing process and the quality of the conclusion.

\section{Part-task practice}

Part-task practice refers to routine aspects of the task that require a high level of automaticity and is therefore appropriate for elements of the learning tasks that are recurrent within task classes (van Merriënboer and Kirschner 2017). Automaticity is necessary so that teachers can focus their attention on the non-recurrent aspects of the tasks. Within the context of video coaching, it can be helpful to design practice tasks that support learners in understanding how to use specific frameworks for reflection, how to identify teaching practices that are in line with those frameworks, or how to focus on student learning while watching the videos. This could help ECTs develop frames of reference for each of the perspectives. In addition, if teachers know and can articulate the different steps in the reflection process, this could help them focus on the cognitive processing that is embedded within each of those steps. Having teachers think aloud about the sequencing of the steps could support the learning of the routines within each of the reflection tasks. The next section will operationalize the instructional design further as concrete building blocks that can be used to implement video coaching practices.

\section{Video coaching with ECTs: reflective practices blueprint}

While the 4C/ID considerations provide a theoretically sound approach to video coaching based on the united reflection model, further operationalization is needed to apply these ideas in practice. This section offers a video coaching blueprint, organized around the three components of a skeleton design (McKenney and Reeves 2019): (1) the activities and tasks (what teachers do), (2) the materials and resources (what tools are used), and (3) the participation and practices (how teachers and coaches participate); see Fig. 3 for highlights. 
Activities \& tasks

\begin{tabular}{|c|c|c|c|c|}
\hline \multirow{3}{*}{ 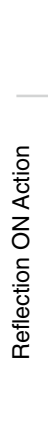 } & & $\begin{array}{l}\text { Preparation, } \\
\text { image forming, } \\
\text { conclusion drawing }\end{array}$ & Support for cognitive processing & Part-task practice \\
\hline & $\begin{array}{l}\frac{0}{0} \\
\frac{0}{0} \\
\frac{1}{0}\end{array}$ & $\begin{array}{l}\text { Deliberate analysis of } \\
\text { past practice to } \\
\text { improve understanding } \\
\text { of ZPP. }\end{array}$ & $\begin{array}{l}\text { Frameworks of effective teaching, } \\
\text { example videos of teachers } \\
\text { engaging in deliberate analysis } \\
\text { of practice, facilitator questions. }\end{array}$ & $\begin{array}{l}\text { Automate identification } \\
\text { of indicators of effective } \\
\text { teaching behaviors using } \\
\text { examples of practice. }\end{array}$ \\
\hline & $\frac{0}{\frac{0}{\pi}}$ & $\begin{array}{l}\text { Explication of practical } \\
\text { awareness during past } \\
\text { practice to improve } \\
\text { understanding of ZPI. }\end{array}$ & $\begin{array}{l}\text { Literature highlighting the importance } \\
\text { of attending to one's context, } \\
\text { example videos of teachers } \\
\text { engaging in explicating practical } \\
\text { awareness, facilitator questions. }\end{array}$ & $\begin{array}{l}\text { Automate a focus on } \\
\text { salient moments. }\end{array}$ \\
\hline \multirow{2}{*}{ 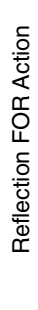 } & 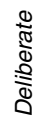 & $\begin{array}{l}\text { Deliberate planning } \\
\text { of future actions to } \\
\text { improve practice } \\
\text { within ZPP. }\end{array}$ & $\begin{array}{l}\text { Frameworks of effective teaching, } \\
\text { example videos of teachers } \\
\text { engaging in deliberate planning } \\
\text { of practice, facilitator questions. }\end{array}$ & Automate planning steps. \\
\hline & 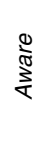 & $\begin{array}{l}\text { Planning future actions } \\
\text { based on awareness } \\
\text { to improve practice } \\
\text { within ZPI. }\end{array}$ & $\begin{array}{l}\text { Literature highlighting the importance } \\
\text { of attending to one's context, example } \\
\text { videos of teachers using } \\
\text { awareness while planning, } \\
\text { facilitator questions. }\end{array}$ & Automate planning steps. \\
\hline \multirow{2}{*}{ 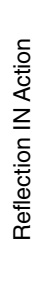 } & 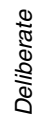 & $\begin{array}{l}\text { Deliberate practice } \\
\text { of actions to improve } \\
\text { performance within } \\
\text { ZPP. }\end{array}$ & $\begin{array}{l}\text { Frameworks of effective teaching, } \\
\text { facilitator questions. }\end{array}$ & $\begin{array}{l}\text { Automate a focus on } \\
\text { specific actions in } \\
\text { (mini)lessons. }\end{array}$ \\
\hline & 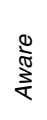 & $\begin{array}{l}\text { Practicing awareness } \\
\text { during action to } \\
\text { improve performance } \\
\text { within ZPI. }\end{array}$ & $\begin{array}{l}\text { Literature highlighting the importance } \\
\text { of attending to one's context, } \\
\text { facilitator questions. }\end{array}$ & $\begin{array}{l}\text { Automate recognition of } \\
\text { salient moments in } \\
\text { (mini)lessons. }\end{array}$ \\
\hline
\end{tabular}

Materials \& resources

\begin{tabular}{|ll}
$\begin{array}{l}\text { Priming } \\
\text { tools }\end{array}$ & $\begin{array}{l}\text { Materials containing teaching } \\
\text { theory, literature on situated } \\
\text { learning, or tools for cognitive } \\
\text { feedback. Used for activation of } \\
\text { prior knowledge and experiences. }\end{array}$ \\
$\begin{array}{l}\text { Examples } \\
\text { of practice }\end{array}$ & $\begin{array}{l}\text { Representations (e.g. video, text) } \\
\text { of teaching, problem solving, or } \\
\text { reflection processes. Used to } \\
\text { practice identification of } \\
\text { (specific) teaching practices. }\end{array}$ \\
\hline $\begin{array}{l}\text { Artifacts } \\
\text { of practice }\end{array}$ & $\begin{array}{l}\text { Products of practice (videoed or } \\
\text { text-based). } \\
\text { Help promote discussions about } \\
\text { practice. }\end{array}$ \\
\hline
\end{tabular}

Participation \& practices

Coordinator Organizes learning opportunities.

Coordinator Determines the appropriate task complexity.

$\begin{array}{ll}\text { Facilitator } & \begin{array}{l}\text { Stimulates and scaffolds teacher } \\ \text { learning. Asks guiding questions. } \\ \text { Models the reflection processes. }\end{array} \\ \text { Curator } & \begin{array}{l}\text { Selects relevant and high-quality } \\ \text { learning materials. Determines the } \\ \text { authenticity of the task. }\end{array} \\ \text { Learner } & \begin{array}{l}\text { Responsible for own professional } \\ \text { development. May also take on the } \\ \text { facilitator role in a group setting. }\end{array}\end{array}$

Fig. 3 Blueprint for video coaching through reflective practices 


\section{Activities and tasks}

The six reflective processes described previously are central to the design (see Fig. 3). Tasks within task classes will always be executed sequentially, but not in a specific order, after which the conclusions are compared. Here, the nature of each task and the potential benefits for the professionalism of ECTs are illustrated.

During RoA, engaging in deliberate analysis of practice is important because it helps realize an essential aspect of professional development, namely, that teachers develop their practices in line with evidence-based frameworks of effective teaching (Pianta et al. 2008). For instance, there might be cases when a teacher questions if his (inter)actions (could) contribute to a positive pedagogical climate. The coach and teacher select a relevant framework as the basis for analysis of videotaped practice, and go through a process of reflection preparation, image forming, and conclusion drawing to determine if the videotaped actions contain evidence of these interactions. In addition, engaging in explicating practical awareness is important because it helps realize an essential aspect of professional development, namely, that teachers study their practice to gain understanding of (difficulties in) student learning, and the implications for their instruction, which can provide incentives for change (Santagata and Bray 2016). For example, suppose that a teacher becomes aware that students do not appear to understand the subject-matter content, but is not sure what exactly is causing the lack of understanding. The coach and teacher decide to study the recorded interactions between students, teacher and materials to better understand what is causing this specific situation. The coach and teacher go through a process of reflection preparation, image forming and conclusion drawing to gain understanding of the situation.

During RfA, engaging in deliberate planning of action is important, because it helps to support an important part of teachers' professional practice, namely, that teachers integrate knowledge of effective teaching practices into their own professional practice (Pianta et al. 2008). For instance, suppose that a teacher and coach have reached the conclusion that the students are spending too much time off-task, which jeopardizes their learning. There is a large research base on strategies to promote on-task behavior by students, which could offer direction for the planning of future lessons. The coach and teacher select a conceptual framework that is thought to be beneficial, and go through a process of reflection preparation, image forming and conclusion drawing to plan future lessons. Moreover, planning based on awareness is a task that can support an important aspect of professional development, because it encourages teachers to make their reasoning about teaching-learning processes explicit, to argue for their convictions, and to share their knowledge (Voogt et al., 2016). To illustrate, suppose that a teacher and coach have determined that students are not very active during the lesson and that much of the lesson consists of teacher-led instruction. The teacher has a number of ideas based upon prior experiences about how future lessons could be designed to support more active behavior. The coach and teacher decide to explore those ideas, and go through a process of reflection preparation, image forming and conclusion drawing to plan future lessons.

During RiA, engaging in deliberate practice could benefit teachers because it incorporates an important component of professional development, namely framing teaching itself as learning opportunity by integrating small experiments or challenges (Bronkhorst et al. 2014). For instance, suppose that a teacher is going to present a lesson during which he will pay specific attention to providing feedback on student work. There is a three-step process that the teacher will carry out during instruction, consisting of providing feedback on the correctness of the answer, clarifying why the answer is correct 
or not and checking if the students understand the explanation. The teacher performs the feedback behavior and monitors its enactment through a process of reflection preparation, image forming, and conclusion drawing in order to regulate, adjust, and improvise further action. Practicing awareness could also support teachers' professional practice, because it could support their ability to notice salient moments during teaching (Sherin and van Es 2009), which could affect their instructional decision-making. To illustrate, the teacher implements lesson activities, and actively monitors students' feelings and actions in order heighten his awareness of external feedback.

\section{Materials and resources}

Three types of materials and resources are essential for supporting video-based reflection (see Fig. 3), which can take the form of supportive information or tools for parttask practice. First, priming tools are (typically text-based) materials that support the learner's cognitive processing, by supporting activation of prior knowledge and experiences to make connections to new understandings (Windschitl et al. 2012). Priming tools, such as observation instruments that align with the collective frameworks for effective teaching, can support cognitive processing, because they help the learner to identify effective teaching practices. In combination with video, priming tools might be beneficial in light of a possible pre-training effect, which is defined as improving learning with multimedia by providing the names and characteristics of the main concepts beforehand, thereby equipping learners with the necessary information for processing the subsequently presented information (Mayer and Pilegard 2014). The literature has suggested that pre-training before multimedia learning can be effective (Mayer and Pilegard 2014), but is not always (e.g., Meyer et al. 2019). For example, it seems less likely that learners who already have knowledge on the subject will benefit from pre-training (Mayer and Pilegard 2014). In addition, guiding questions that support the comparison of the framework with practice can support teachers in reasoning about the connection between the two. For the aware perspective, there are no specific frameworks to guide problem solving, but the literature on noticing has indicated that guiding questions can support teacher thinking about student learning (Sherin and van Es 2009; van Es and Sherin 2008).

Second, examples of practice are text-based or videotaped examples of effective teaching and learning, which help bridge the gap between theory and application (van Merriënboer and Kirschner 2017). These can be used during part-task practice to automate the identification of effective teaching practices using explicit frameworks of effective teaching. Alternatively, examples of practice can be understood as videotaped modelled reflection processes, that is, where an expert or coach models how to compare perspectives during RoA, RfA, and RiA.

Third, artifacts of practice are products of the teaching practice (videotaped or textbased), which can serve as vehicle for reflection (Herbst and Kosko 2014). Videos of teaching practice can be analyzed and compared to frameworks for effective teaching (deliberate perspective) and used to derive contextualized knowledge (aware perspective) in RoA tasks. During RfA, it can be productive to analyze pre-existing lesson plans or other curriculum materials produced by the teachers as a starting point for planning. During RiA tasks, lesson plans or other materials can be used to guide monitoring of specific actions (deliberate perspective). 


\section{Participation and practices}

Coaching ECTs requires individual approaches to learning to meet the teachers' personal development needs, which requires coaches to fulfil different roles. Here, three roles are distinguished for coaches: coordinator, facilitator, and curator. In addition, the role of the coachee is also described (see Fig. 3).

The coordinator is responsible for organizing learning opportunities and determines the appropriate task complexity. The coordinator consults with the individual teachers to determine the learning objectives and plans appropriate learning tasks. The coordinator helps teachers to determine and formulate reflection questions that can be used as input for the reflection activities.

The facilitator is responsible for stimulating teachers' learning and scaffolds the appropriate level of support. The facilitator supports cognitive processes during RoA, RfA, and $\mathrm{RiA}$ activities by prompting teacher thinking through (non)verbal interaction or through the presentation of priming tools during video coaching. The facilitator fulfils the role of an expert, who supports teachers in noticing important salient teaching moments that might be overlooked (e.g., Sherin and van Es 2009; van Es and Sherin 2008). Facilitators could also provide cognitive feedback on the problem solving within reflection tasks, by detailing their own framing, interpretation and conclusion drawing, or inviting peers to share their reflections, after which these can be compared. The facilitator supports the development of knowledge based on united perspectives.

The curator is responsible for selecting relevant and high-quality learning materials and determines the authenticity of the task. The curator selects the materials, supports production of them, and presents relevant and high-quality materials as input for coaching activities. Relevant types of materials include: (1) priming tools that can support teacher thinking prior to and during activities and that can take the form of questions or materials presented to the learner that help them unpack explicit or tacit understandings (Windschitl et al. 2012), (2) artifacts of practice that can be used as input for reflection activities and that connect to the coaching objectives, and (3) examples that can be used to illustrate productive reflection processes or that can serve as input for reflection activities in the initial sessions of the training.

The learner is responsible for managing learning behavior during engagement with the different activities and tasks. In some situations, learners may support the professional growth of their peers by taking on the role of co-facilitator. Within this co-facilitator role, the learner could: ask questions to unpack problems (problem-solving support), model activities and tasks (examples), and share confirming or contrasting observations (cognitive feedback).

\section{Discussion}

\section{Significance}

This article aims to contribute to thinking about the way epistemological views shape teacher training and education, by illustrating how uniting two differing epistemological perspectives on teachers' knowledge development could be possible and even beneficial for reflection. The deliberate perspective, aligned with empiricism, stresses the knowing 
that comes from systematic observation, while the aware perspective, aligned with rationalism, stresses the knowing that is derived from organic forms of perception. Both perspectives can clearly be intentional. Kirschner (2009) reminded us that we should take the level of expertise of the learner into account when designing instruction, and thus not ignore the psychological bases of learning and pedagogy due to epistemological beliefs. He also noted that both epistemological perspectives have value and that (while wanting to avoid ideological discussions): "Of course, we, as rational right-minded people, know that neither faction is correct and that the "truth" lies in the middle" (p. 144). In a similar vein, this article illustrates how uniting two different epistemological perspectives presents added value for ECT knowledge development and use. It builds upon earlier work from scholars who advocated the integration of perspectives (Carlson and Daehler 2019; Depaepe et al. 2013; Kaiser et al. 2017), and scholars who have written about reflection in the past (e.g., Hatton and Smith 1995; Jay and Johnson 2002; Schön 1983, 1995; van Manen 1977). At the same time, it acknowledges that some scholars have noted potential tensions between the perspectives. For example, while research has identified specific teaching practices that are effective (Muijs and Reynolds 2018), over-reliance on this work alone would fail to capture the complex nature of teaching (cf. Schön 1995; van Manen 1977). Further, this article articulates three important types of reflection, and describes specific steps for undertaking each in united ways.

\section{Implications}

Uniting perspectives holds implications for the design of teacher education and teacher professional development trajectories. Acknowledging that teacher education should incorporate opportunities for development of both types of knowledge and for uniting the two, while taking into account the experience level of the learners, has consequences for the content and the operationalization of support. Pre-service teachers are still learning to teach, and much of their training should be focused on collective knowledge acquisition, while also including opportunities to develop their teaching repertoire, as well as the tools to study their own practice (Feiman-Nemser 2001). Teacher educators could implement the united reflection model by incorporating teacher training qualification standards for reflection tasks from a deliberate perspective, while taking an aware perspective to reflect on student learning. In comparing the conclusions from both the aware and the deliberate perspectives, pre-service teachers could develop reflective abilities and routines. These could be used, for example, to support their investigation of student learning resulting from performing effective teaching behaviors as depicted by teacher qualification standards. This could be especially beneficial for novice teachers, because research has shown that they often focus on surface-level events, such as student behaviors and disruptions, instead of attending to student learning as expert teachers do (Wolff et al. 2017). In addition, coaching and reflection can support the belief that learning is an essential part of teaching and necessary for the development of their practice (Feiman-Nemser 2001).

Further, we have argued that teachers at the beginning stages of their careers, that is ECTs, can benefit from integrating both perspectives within reflection, because doing so allows them to develop and sustain effective teaching practices, while also negotiating their teacher identities. ECTs experience tensions in the beginning stages of their teaching careers, such as the tension between what they desire to accomplish during their teaching and what is possible in reality (Pillen et al. 2013). Taking a united approach to reflection could allow teachers to question their own practices in light of standards of effective 
teaching, and in light of the contextual opportunities and constraints, providing an opportunity to explore these tensions. Exploring tensions through discussion could strengthen their identities as teachers and support the development of coping strategies (Pillen et al. 2013). The attention to identity development can in turn support teacher resilience, especially when this is explored in relationships with others (Pearce and Morrison 2011). However, it should be noted that a focus on developing personal resources alone is not sufficient to support teacher resilience, and contextual factors, such as school culture and support from school management, should be taken into account as well (Ainsworth and Oldfield 2019; Johnson et al. 2014).

Finally, uniting perspectives within reflection could support experienced teachers to integrate new evidence-based practices into their teaching in order to strengthen their professionalism. Strengthening and refining their practice (Feiman-Nemser 2001) might require the incorporation of additional evidence-based practices and more detailed study of how these actually contribute to student learning within specific contexts. These refinements often occur through changes in the school vision or through reform, and understanding the opportunities and constraints of the local context will be needed to implement changes that are efficient and feasible. Teacher coaches or teacher leaders could incorporate the united reflection model by using the newly adopted standards to reflect from a deliberate perspective, while the aware perspective could be adopted to focus on the interplay between the students, other colleagues, the classroom setting and the larger organizational setting to gain understanding of how these standards can be enacted in practice to fit the local context. Within these settings, the coach's role can be played by other teachers, who are all working together to improve their practice.

\section{Future directions}

More research based upon the united reflection model is needed to strengthen the theoretical understanding of the interplay between knowledge bases and of how contextualized knowledge can be measured and developed in training settings, throughout the course of a teaching career. Research by Kaiser et al. (2017) has illustrated that there are different aspects of teachers' knowledge, which require different measurement instruments and methods. However, in line with the argument presented, other instruments might be needed that do justice to measuring the newly contextualized knowledge after reflecting on past practice, after planning future practices, and during teaching. Expert-novice research has shown that expert teachers draw from their integrated knowledge in order to perceive, interpret and predict teaching situations (Wolff et al. 2015) and subsequently use this information to propose alternatives. But further work is needed to identify ways to better support novices who lack such experience.

This article articulates promising directions for professional development trajectories by supporting teachers in uniting their deliberate and aware perspectives, but these ideas need to be developed and tested in practice under different conditions and with teachers at different stages of their teaching careers. Education for pre-service teachers and more experienced teachers using the united reflection model can be enacted using different artifacts, such as videos, lesson observations, or student work, and the conversations can take place in online or face-to-face settings, depending on the contextual needs and constraints. The development of interventions could especially benefit from the knowledge and experience of coaches, teacher leaders, and teacher educators as co-designers in order to operationalize the model. Specifically, they could contribute by jointly developing domain-specific 
information, procedural information, part-task practice items, and support for coaches in order to enhance the usability, feasibility, and viability of implementation of the operationalized model in practice. Ecologically valid studies to iteratively test the model in different manifestations or settings could be especially beneficial next steps, because they could provide insight into (1) to what extent and in what way the model supports contextual knowledge development, and (2) the experiences of coaches and teachers enacting the model. The outcomes of those studies could be used to revise the design, to develop initial design guidelines for implementation in practice, and to set the stage for larger experimental studies of effectiveness. In so doing, it seems prudent to anticipate that the reflective processes enacted will rarely flow as cleanly as depicted in the model; for instance, coaches and teachers might go back and forth between framing and image forming before drawing final conclusions.

In conclusion, before it is worth knowing anything else, one must come to know oneself, as described in Plato's Phaedrus (229e-230a, trans. 1925), and this idea seems especially important for those who serve others. Understanding oneself in relation to collective knowledge bases (what constitutes good teaching) and in relation to educational contexts (where am I teaching) is argued to be important for continued development as a teacher and considered central to the united reflection model. Reflection can provide opportunities to unpack the knowledge and beliefs teachers hold about teaching and learning processes and the educational context, and to (possibly) review them in light of collective knowledge of teaching. As such, uniting perspectives on reflection can provide opportunities to question existing ideas and practices, and opportunities for development throughout a teaching career.

Funding This research was supported by a grant from the Dutch Ministry of Education, Culture and Science as part of the project Begeleiding Startende Leraren, Meesterschap Oost, project number BSL2013-06.

\section{Compliance with ethical standards}

Conflict of interest The authors declare that they have no conflict of interest.

Ethical approval This article does not report on any studies with human participants or animals performed by any of the authors.

Open Access This article is licensed under a Creative Commons Attribution 4.0 International License, which permits use, sharing, adaptation, distribution and reproduction in any medium or format, as long as you give appropriate credit to the original author(s) and the source, provide a link to the Creative Commons licence, and indicate if changes were made. The images or other third party material in this article are included in the article's Creative Commons licence, unless indicated otherwise in a credit line to the material. If material is not included in the article's Creative Commons licence and your intended use is not permitted by statutory regulation or exceeds the permitted use, you will need to obtain permission directly from the copyright holder. To view a copy of this licence, visit http://creativecommons.org/licenses/by/4.0/.

\section{References}

Ainsworth, S., \& Oldfield, J. (2019). Quantifying teacher resilience: Context matters. Teaching and Teacher Education, 82, 117-128. https://doi.org/10.1016/j.tate.2019.03.012. 
Berland, L. K., \& Hammer, D. (2012). Framing for scientific argumentation. Journal of Research in Science Teaching, 49(1), 68-94. https://doi.org/10.1002/tea.20446.

Biesta, G., Priestley, M., \& Robinson, S. (2017). Talking about education: Exploring the significance of teachers' talk for teacher agency. Journal of Curriculum Studies, 49(1), 38-54. https://doi. org/10.1080/00220272.2016.1205143.

Blömeke, S., Gustafsson, J. E., \& Shavelson, R. J. (2015). Beyond dichotomies. Zeitschrift für Psychologie, 223(1), 3-13. https://doi.org/10.1027/2151-2604/a000194.

Boschman, F., McKenney, S., \& Voogt, J. (2014). Understanding decision making in teachers' curriculum design approaches. Educational Technology Research and Development, 62(4), 393-416. https://doi. org/10.1007/s11423-014-9341-X.

Bronkhorst, L. H., Meijer, P. C., Koster, B., \& Vermunt, J. D. (2014). Deliberate practice in teacher education. European Journal of Teacher Education, 37(1), 18-34. https://doi.org/10.1080/02619 768.2013 .825242 .

Brown, J. S., Collins, A., \& Duguid, P. (1989). Situated cognition and the culture of learning. Educational Researcher, 18(1), 32-42. https://doi.org/10.3102/0013189X018001032.

Buchanan, R. (2015). Teacher identity and agency in an era of accountability. Teachers and Teaching, 21(6), 700-719. https://doi.org/10.1080/13540602.2015.1044329.

Carlson, J., \& Daehler, K. R. (2019). The refined consensus model of pedagogical content knowledge in science education. In A. Hume, R. Cooper, \& A. Borowski (Eds.), Repositioning pedagogical content knowledge in teachers' knowledge for teaching science (pp. 77-92). Singapore: Springer.

Clarke, D., \& Hollingsworth, H. (2002). Elaborating a model of teacher professional growth. Teaching and Teacher Education, 18(8), 947-967. https://doi.org/10.1016/S0742-051X(02)00053-7.

den Brok, P., Wubbels, T., \& van Tartwijk, J. (2017). Exploring beginning teachers' attrition in the Netherlands. Teachers and Teaching, 23(8), 881-895. https://doi.org/10.1080/13540602.2017.1360859.

Depaepe, F., Verschaffel, L., \& Kelchtermans, G. (2013). Pedagogical content knowledge: A systematic review of the way in which the concept has pervaded mathematics educational research. Teaching and Teacher Education, 34, 12-25. https://doi.org/10.1016/j.tate.2013.03.001.

Dewey, J. (1933). How we think: A restatement of the relation of reflective thinking to the educative process. Boston: DC Heath and Company.

Dewey, J. (1938). Logic: The theory of inquiry. New York, NY: Holt, Rinehart and Winston.

Eraut, M. (2000). Non-formal learning and tacit knowledge in professional work. British Journal of Educational Psychology, 70(1), 113-136. https://doi.org/10.1348/000709900158001.

Feiman-Nemser, S. (2001). From preparation to practice: Designing a continuum to strengthen and sustain teaching. Teachers College Record, 103(6), 1013-1055.

Gelfuso, A., \& Dennis, D. V. (2014). Getting reflection off the page: The challenges of developing support structures for pre-service teacher reflection. Teaching and Teacher Education, 38, 1-11. https://doi. org/10.1016/j.tate.2013.10.012.

Hanushek, E. A., \& Rivkin, S. G. (2010). The quality and distribution of teachers under the No Child Left Behind Act. Journal of Economic Perspectives, 24(3), 133-150. https://doi.org/10.1257/jep.24.3.133.

Harris, J., \& Hofer, M. (March 2009). Instructional planning activity types as vehicles for curriculum-based TPACK development. In Society for Information Technology \& Teacher Education International Conference (pp. 4087-4095). Association for the Advancement of Computing in Education (AACE).

Hatton, N., \& Smith, D. (1995). Reflection in teacher education: Towards definition and implementation. Teaching and Teacher Education, 11(1), 33-49. https://doi.org/10.1016/0742-051X(94)00012-U.

Herbst, P., \& Kosko, K. W. (2014). Using representations of practice to elicit mathematics teachers' tacit knowledge of practice: a comparison of responses to animations and videos. Journal of Mathematics Teacher Education, 17(6), 515-537. https://doi.org/10.1007/s10857-013-9267-y.

Hoffman-Kipp, P., Artiles, A. J., \& Lopez-Torres, L. (2010). Beyond reflection: Teacher learning as praxis. Theory into Practice, 42(3), 248-254. https://doi.org/10.1207/s15430421tip4203_12.

Jay, J. K., \& Johnson, K. L. (2002). Capturing complexity: A typology of reflective practice for teacher education. Teaching and Teacher Education, 18(1), 73-85. https://doi.org/10.1016/S0742-051X(01)00051 -8 .

Johnson, B., Down, B., Le Cornu, R., Peters, J., Sullivan, A., Pearce, J., et al. (2014). Promoting early career teacher resilience: A framework for understanding and acting. Teachers and Teaching, 20(5), 530-546. https://doi.org/10.1080/13540602.2014.937957.

Jonassen, D. H., \& Ionas, I. G. (2008). Designing effective supports for causal reasoning. Educational Technology Research and Development, 56(3), 287-308. https://doi.org/10.1007/s11423-006-9021-6.

Kaiser, G., Blömeke, S., König, J., Busse, A., Doehrmann, M., \& Hoth, J. (2017). Professional competencies of (prospective) mathematics teachers-Cognitive versus situated approaches. Educational Studies in Mathematics, 94(2), 161-182. https://doi.org/10.1007/s10649-016-9713-8. 
Kaiser, G., Busse, A., Hoth, J., König, J., \& Blömeke, S. (2015). About the complexities of video-based assessments: Theoretical and methodological approaches to overcoming shortcomings of research on teachers' competence. International Journal of Science and Mathematics Education, 13(2), 369-387. https://doi.org/10.1007/s10763-015-9616-7.

Kirschner, P. A. (2009). Epistemology or pedagogy, that is the question. In S. Tobias \& T. M. Duffy (Eds.), Constructivist instruction: Success or failure? (pp. 144-157). New York: Routledge.

Krathwohl, D. R. (2002). A revision of Bloom's taxonomy: An overview. Theory into Practice, 41(4), 212218. https://doi.org/10.1207/s15430421tip4104_2.

Lave, J., \& Wenger, E. (1991). Situated learning: Legitimate peripheral participation. Cambridge, UK: Cambridge University Press.

Lindsay, A., \& Mason, R. (2000). Focusing on reflection with early childhood practitioners. Networks: An Online Journal for Teacher Research, 3(2), 138-138. https://doi.org/10.4148/2470-6353.1218.

Loughran, J. J. (1996). Developing reflective practice: Learning about teaching and learning through modelling. Abingdon: Routledge Falmer.

Loughran, J., Mulhall, P., \& Berry, A. (2008). Exploring pedagogical content knowledge in science teacher education. International Journal of Science Education, 30(10), 1301-1320. https://doi. org/10.1080/09500690802187009.

Marsh, B., \& Mitchell, N. (2014). The role of video in teacher professional development. Teacher Development, 18(3), 403-417. https://doi.org/10.1080/13664530.2014.938106.

Maulana, R., Opdenakker, M. C., Stroet, K., \& Bosker, R. (2012). Observed lesson structure during the first year of secondary education: Exploration of change and link with academic engagement. Teaching and Teacher Education, 28(6), 835-850. https://doi.org/10.1016/j.tate.2012.03.005.

März, V., \& Kelchtermans, G. (2013). Sense-making and structure in teachers' reception of educational reform. A case study on statistics in the mathematics curriculum. Teaching and Teacher Education, 29, 13-24. https://doi.org/10.1016/j.tate.2012.08.004.

Mayer, R., \& Pilegard, C. (2014). Principles for managing essential processing in multimedia learning: Segmenting, pre-training, and modality principles. In R. Mayer (Ed.), The Cambridge handbook of multimedia learning (pp. 316-344). Cambridge: Cambridge University Press.

McKenney, S. (2013). Designing and researching technology-enhanced learning for the zone of proximal implementation. Research in Learning Technology. https://doi.org/10.3402/rlt.v21i0.17374.

McKenney, S., \& Reeves, T. C. (2019). Conducting educational design research. London: Routledge.

Mezirow, J. (1991). Transformative dimensions of adult learning. San Francisco: Jossey-Bass.

Meyer, O. A., Omdahl, M. K., \& Makransky, G. (2019). Investigating the effect of pre-training when learning through immersive virtual reality and video: A media and methods experiment. Computers \& Education, 140, 103603. https://doi.org/10.1016/j.compedu.2019.103603.

Muijs, D., \& Reynolds, D. (2018). Effective teaching: Evidence and practice (4th ed.). London: Sage.

Ovens, A. (July 2002). Discourse communities and the social construction of reflection in teacher education. In Quality Conversations, Annual International Conference of the Higher Educational Research and Development Society (pp. 7-10).

Pearce, J., \& Morrison, C. (2011). Teacher identity and early career resilience: Exploring the links. Australian Journal of Teacher Education (Online), 36(1), 48.

Pianta, R. C., Mashburn, A. J., Downer, J. T., Hamre, B. K., \& Justice, L. (2008). Effects of web-mediated professional development resources on teacher-child interactions in pre-kindergarten classrooms. Early Childhood Research Quarterly, 23(4), 431-451. https://doi.org/10.1016/j.ecresq.2008.02.001.

Pillen, M., Beijaard, D., \& den Brok, P. (2013). Tensions in beginning teachers' professional identity development, accompanying feelings and coping strategies. European Journal of Teacher Education, 36(3), 240-260. https://doi.org/10.1080/02619768.2012.696192.

Polanyi, M. (1967). The tacit dimension. Garden City, NY: Doubleday.

Reymen, I. M. M. J., Hammer, D. K., Kroes, P. A., van Aken, J. E., Dorst, C. H., Bax, M. F. T., et al. (2006). A domain-independent descriptive design model and its application to structured reflection on design processes. Research in Engineering Design, 16(4), 147-173. https://doi.org/10.1007/s0016 3-006-0011-9.

Russ, R. S., \& Luna, M. J. (2013). Inferring teacher epistemological framing from local patterns in teacher noticing. Journal of Research in Science Teaching, 50(3), 284-314. https://doi.org/10.1002/tea.21063.

Santagata, R., \& Bray, W. (2016). Professional development processes that promote teacher change: The case of a video-based program focused on leveraging students' mathematical errors. Professional Development in Education, 42(4), 547-568. https://doi.org/10.1080/19415257.2015.1082076.

Santagata, R., \& Yeh, C. (2016). The role of perception, interpretation, and decision making in the development of beginning teachers' competence. ZDM Mathematics Education, 48(1-2), 153-165. https://doi. org/10.1007/s11858-015-0737-9. 
Schön, D. A. (1983). The reflective practitioner. New York, NY: Basic Books.

Schön, D. A. (1995). Knowing-in-action: The new scholarship requires a new epistemology. Change: The Magazine of Higher Learning, 27(6), 27-34. https://doi.org/10.1080/00091383.1995.10544673.

Sherin, M., \& van Es, E. A. (2009). Effects of video club participation on teachers' professional vision. Journal of Teacher Education, 60(1), 20-37. https://doi.org/10.1177/0022487108328155.

Shulman, L. (1987). Knowledge and teaching: Foundations of the new reform. Harvard Educational Review, 57(1), 1-23. https://doi.org/10.17763/haer.57.1.j463w79r56455411.

Sipman, G., Thölke, J., Martens, R., \& McKenney, S. (2019). The role of intuition in pedagogical tact: Educator views. British Educational Research Journal, 45(6), 1186-1202. https://doi.org/10.1002/ berj.3557.

Smith, K. (February 2014). One a teacher, always a teacher? Examining teacher attrition in a Norwegian and international perspective. Application submitted to the Norwegian research council, FINNUT program. Bergen: University of Bergen.

Sumner, M. (2006). Epistemology. In V. Jupp (Ed.), The SAGE dictionary of social research methods (pp. 93-94). London: SAGE Publications Ltd.

Van de Grift, W. (2010). Ontwikkeling van de beroepsvaardigheden van leraren [Development of teaching skills] (Inauguration speech). University of Groningen, Groningen. Retrieved from https://www.rug.nl/ gmw/lerarenopleiding/docs/oratievandegrift.pdf.

van der Lans, R. M., van de Grift, W. J., \& Van Veen, K. (2018). Developing an instrument for teacher feedback: using the Rasch model to explore teachers' development of effective teaching strategies and behaviors. The Journal of Experimental Education, 86(2), 247-264. https://doi.org/10.1080/00220 973.2016.1268086.

van der Linden, S., van der Meij, J. \& McKenney, S. (manuscript in preparation). A systematic review of video coaching: From design to impact.

van Es, E. A., \& Sherin, M. G. (2008). Mathematics teachers' "learning to notice" in the context of a video club. Teaching and Teacher Education, 24(2), 244-276. https://doi.org/10.1016/j.tate.2006.11.005.

van Manen, M. (1977). Linking ways of knowing with ways of being practical. Curriculum Inquiry, 6(3), 205-228. https://doi.org/10.1080/03626784.1977.11075533.

van Merriënboer, J. J., \& Kirschner, P. A. (2017). Ten steps to complex learning: A systematic approach to four-component instructional design. New York, NY: Routledge.

Voogt, J. M., Pieters, J. M., \& Handelzalts, A. (2016). Teacher collaboration in curriculum design teams: Effects, mechanisms, and conditions. Educational Research and Evaluation, 22(3-4), 121-140. https:// doi.org/10.1080/13803611.2016.1247725.

Vygotsky, L. S. (1978). Mind in society: the development of higher mental processes. Cambridge: Harvard University Press.

Wallin, A. J., \& Amador, J. M. (2019). Supporting secondary rural teachers' development of noticing and pedagogical design capacity through video clubs. Journal of Mathematics Teacher Education, 22(5), 515-540. https://doi.org/10.1007/s10857-018-9397-3.

Walsh, M., Matsumura, L. C., Zook-Howell, D., Correnti, R., \& Bickel, D. D. (2020). Video-based literacy coaching to develop teachers' professional vision for dialogic classroom text discussions. Teaching and Teacher Education, 89, 103001. https://doi.org/10.1016/j.tate.2019.103001.

Windschitl, M., Thompson, J., Braaten, M., \& Stroupe, D. (2012). Proposing a core set of instructional practices and tools for teachers of science. Science Education, 96(5), 878-903. https://doi.org/10.1002/ sce. 21027.

Wolff, C. E., Jarodzka, H., \& Boshuizen, H. P. (2017). See and tell: Differences between expert and novice teachers' interpretations of problematic classroom management events. Teaching and Teacher Education, 66, 295-308. https://doi.org/10.1016/j.tate.2017.04.015.

Wolff, C. E., van den Bogert, N., Jarodzka, H., \& Boshuizen, H. P. (2015). Keeping an eye on learning: Differences between expert and novice teachers' representations of classroom management events. Journal of Teacher Education, 66(1), 68-85. https://doi.org/10.1177/0022487114549810.

Publisher's Note Springer Nature remains neutral with regard to jurisdictional claims in published maps and institutional affiliations.

Sara van der Linden is a PhD candidate at the University of Twente. Her research focuses on the design of video coaching to support the professional development of (early career) teachers. 
Susan McKenney is professor of teacher professionalization, school development and educational technology at the University of Twente in the Netherlands. Her research focuses on these three themes, especially in relation to curriculum design. 